\title{
Genotoxicity and Carcinogenicity of Medicinal Herbs and Their Nanoparticles
}

\author{
Sameer H. Qari ${ }^{1, *(\mathbb{D}}$, Abdulmajeed F. Alrefaei ${ }^{1}\left(\mathbb{D}\right.$, Ahmed B. Ashoor $^{1}$ and Mona H. Soliman ${ }^{2}(\mathbb{D}$ \\ 1 Biology Department, Aljumum University College, Umm Al-Qura University, Makkah 2203, Saudi Arabia; \\ afrefaei@uqu.edu.sa (A.F.A.); s44181957@st.uqu.edu.sa (A.B.A.) \\ 2 Biology Department, Faculty of Science, Taibah University, Al-Sharm, Yanbu El-Bahr, \\ Yanbu 46429, Saudi Arabia; monahsh1@gmail.com \\ * Correspondence: shqari@uqu.edu.sa
}

Citation: Qari, S.H.; Alrefaei, A.F.; Ashoor, A.B.; Soliman, M.H. Genotoxicity and Carcinogenicity of Medicinal Herbs and Their Nanoparticles. Nutraceuticals 2021, 1, 31-41. https://doi.org/10.3390/ nutraceuticals1010005

Academic Editor: Herbert Ryan Marini

Received: 4 October 2021

Accepted: 11 November 2021

Published: 18 November 2021

Publisher's Note: MDPI stays neutral with regard to jurisdictional claims in published maps and institutional affiliations.

Copyright: (C) 2021 by the authors. Licensee MDPI, Basel, Switzerland. This article is an open access article distributed under the terms and conditions of the Creative Commons Attribution (CC BY) license (https:/ / creativecommons.org/licenses/by/ $4.0 /)$.

\begin{abstract}
Medicinal plants (MPs) account for $70-80 \%$ of use in primary care around the world, and this percentage indicates that the number of MP users is high; thus, it is necessary to focus studies on medicinal herbs to ensure their proper use. In addition, MPs have strong genotoxic effects, as some types of MPs can cause DNA damage. Any substance that raises the risk of cancer or a tumor in an organism is called a carcinogen. There are many genotoxic and carcinogenic substances in the environment that can directly or indirectly affect genetic material. There are also nanoparticles (NPs) derived from MPs. Carbon-based NPs contain many nanoscale materials, such as fullerenes and carbon nanotubes, as well as metals such as gold ( $\mathrm{Au})$, silver (Ag), and aluminum (Al). Unfortunately, few studies are concerned with the carcinogenicity of NPs from MPs, whereas many researchers are interested in genotoxic assessment. For this reason, there is an urgent need for more studies into the safety of MPs and NPs. Therefore, this study reviewed the genotoxicity and carcinogenicity of MPs and their derived NPs. We also emphasized the need for strict regulation and monitoring of MP usage.
\end{abstract}

Keywords: genotoxicity; carcinogenicity; nanoparticles; medicinal herbs; DNA damage

\section{Introduction}

The first remedies that humans used were medicinal herbs [1]. Medicinal plants (MPs) are used all over the world, and interest in them began in developed countries in recent years [2]. Because of the economic and health benefits to countries, the percentage of those who use MPs in primary care is indicated to be between $70 \%$ and $80 \%$ [3]. This percentage indicates that users of MPs are highly significant. Therefore, the field needs more studies to ensure the safety of these medicinal plants. There are also many tests to evaluate genotoxicity, some of which are used at the molecular level and some at the chromosome level; these tests are used to detect the genetic toxicity that occurs from many causes, such as chemicals and some types of compounds derived from MPs.

Nanotechnology is an interdisciplinary science that can be defined as the design, synthesis, and application of materials and devices at the nanoscale level in different fields, including medicine, biology, physics, chemistry, and medicine [4,5]. Different types of nanomaterials of a wide range of sizes and shapes have been exploited in various fields of science. The global nanotechnology industry is expected to reach its climax by 2020 [6]. The emerging field of interest in nanoscience is due to the unique physical, chemical, and natural properties of nanomaterials compared to those of bulk materials [5].

There are two methods of obtaining micronutrient powders (MNPs): the top-down approach, and the bottom-up approach. In the top-down approach, MNPs are synthesized by cutting bulk materials via various mechanical procedures to produce nanostructures. In the bottom-up approach, the MNPs are synthesized at the molecular level via different chemical or biological procedures [6,7]. Among the biological, chemical, and physical methods of 
micronutrient powder synthesis, biological methods are bottom-up approaches that overcome some of the unsatisfactory conditions of the physical and chemical methods $[6,8,9]$. Nanobiotechnology studies are classified as "golden biotechnology" studies, and involve synthesis of MNPs by exploiting biological resources [10]. A number of plants [11,12] algae, fungi, and bacteria [13-16] have been reported as more environmentally friendly, biocompatible, and inexpensive alternatives to MNP synthesis than traditional physical and chemical methods. It should be noted that MNPs have been used for wound dressings, cell marking, optical imaging, sensors, drug delivery, gene delivery, etc. [6]. Various extracts obtained from different plant families have shown promising results in treating various human diseases. For example, the antimicrobial activity of chloroform extracts of the leaves of Drosera peltata (Droseraceae) for the treatment of dental problems has been validated [17]. Tichy and Novak (1998) investigated the potentiality of 27 medicinal plant extracts against the growth of dental pathogens [18]. The most active extracts included those from the plants of Abies canadensis (Pinaceae), Albizia julibrissin (Fabaceae), Chelidonium majus (Papaveraceae), Ginkgo biloba (Ginkgoaceae), Juniperus virginiana (Cupressaceae), Pinus virginiana (Pinaceae), Rosmarinus officinalis (Lamiaceae), Sassafras albidum (Lauraceae), Tanacetum vulgare (Asteraceae), and Thuja plicata (Cupressaceae). Further investigation revealed that various extracts possess common antimicrobial components, while other extracts have distinct chemical constituents. In recent times, the emergence of the severe acute respiratory syndrome-related coronavirus 2 (SARS-CoV-2), or novel coronavirus (COVID-19), has been declared as a world pandemic with a high mortality rate. Despite several molecules/vaccines being tested, no effective vaccines or specific treatments have been recommended. It has been proposed that several MPs are sources of active natural molecules/products against COVID-19 [19]. However, some studies report the toxicity and other issues of extracts of herbal MPs [20-22]. Nevertheless, cytotoxic effects such as cell death, the production of reactive oxygen species (ROS), lipid peroxidation (LPO), mitochondrial membrane potential, lysosomal membrane integrity, and the amount of reduced and oxidized glutathione (GSH) of concentration-dependent rizatriptan were investigated in the hepatocytes of rats. It was revealed that the rizatriptan-induced cytotoxicity towards hepatocytes was regulated by oxidative stress and that the mitochondria and lysosomes exhibited a modulatory role [23]. In another study [24], studied the toxic effects of bupropion in rat cells. The parameters such as death of cells, LDH leakage, ROS and LPO formation, and mitochondrial depolarization were examined as oxidative stress markers. The results showed that bupropion-induced ROS and LPO formation depleted the content of GSH, and also increased mitochondrial collapse. However, the toxic effects of bupropion were reversed by $\alpha$-tocopherol succinate, $\mathrm{N}$-acetyl cysteine, and the mitochondrial permeability transition pore sealing agent cyclosporine A. It was, however, postulated that mitochondria could participate in the oxidative stress response and the bupropion-induced toxicological effects.

\subsection{Genotoxicity and Mutagenicity of Medicinal Plants}

There are many different definitions of genotoxicity, but we can summarize the definition of genotoxicity as a chemical agent having the potential to cause damage to DNA or chromosomes [25]. This can cause mutation and may be caused by chemical or radiation agents, such as ultraviolet (UV) and ionizing radiation. Genotoxicity can also repair mutations by direct repair such as nucleotide excision repair (NER) or base excision repair (BER), or persist in somatic cells and cause genetic diseases, or may be germ cells in one specific gene. It causes many genetic diseases, such as sickle cell anemia and diseases caused by multiple factors such as diabetes or cardiovascular diseases [26]. The mutagenicity is caused by chemical compounds or sources of radiation, such as UV light or X-rays, that induce permanent and inherited modifications (mutations) in the cellular genetic material [27]. Mutagenicity has also been defined as genotoxicity, but the essential point is that all mutants are genotoxic in nature, whereas not all genotoxic substances are mutagenic, although the mutations are dangerous. However, we are exposed to daily threats such as 
UV or X-rays, which can cause mutations and carcinogenicity [28]. There are many types of mutagens. The first are physical mutagens, including electromagnetic radiation [29], which are categorized into two sections: ionizing and non-ionizing radiation. Ionizing radiation can be particulate (alpha particles and beta particles, or fast neutrons), which can emit either natural or artificial sources; and non-particulate (X-rays and $\gamma$-rays). Non-ionizing radiation includes UV rays [30].

The second type of mutagens to cause mutations are chemical mutagens. Chemical mutagens are classified into four different categories. The first category is base analogs, referring to compounds of a chemical nature that have similarity to one of the four DNA bases. Base analogs can be integrated to increase the polynucleotide chain during the normal process of replication, replacing the bases and causing a stable mutation. The most-studied base analogs include halouracils uridine derivatives that have 5-bromouracil (5-BU), which is a thymine analog of the 5-BU and shows pairing with adenine [30,31].

The second category includes chemicals that induce changes in the properties of hydrogen bonding, such as nitrous oxide, which induces changes in the set of amino bases and converts them into the keto group by removing oxidation. It leads to the deamination of adenine, cytosine, and guanine, and causes the hydroxylation of cytosine at the $\mathrm{C}_{4}$ nitrogen and transforms it into a transformed base by deamination that causes base pairs such as thiamine and sodium azide, found in automobile airbags and in other industries [32], Sodium azide causes mutations in genetic material such as in the ANT18 gene of barley, according to some studies [33]. The third category consists of intercalating compounds, which are certain dyes like acridine orange, proflavine, and acriflavine. These are threeringed molecules with a similar shape to purine-pyrimidine pairs, in aqueous solution. These dyes can be inserted into the bases of DNA in adjacent pairs by a process known as intercalation. Hence, these dyes are called intercalating agents and they cause frameshift mutations.

The fourth category is alkylating agents-compounds that add an alkylating group to the DNA molecule at its guanine base, preventing double helix strands from connecting, thus causing a breakup of the DNA strands, which affects the multiplication capability of the cancer cells. Thus, the cancer cells will eventually die. In cancer therapy, alkylating agents were one of the first classes of drugs to be used. There are five types of these agents: nitrogen mustards, such as chlorambucil, bendamustine, cyclophosphamide, mechlorethamine, ifosfamide, and melphalan; nitrosoureas, such as lomustine, streptozocin, and carmustine; alkyl sulfonates, such as busulfan; triazines, such as dacarbazine and temozolomide; and ethylenimines, such as altretamine and thiotepa.

The third type of biological mutagens are agents such as viruses, transposons, and bacteria. It has been reported that both viral DNA and transposons can be inserted into the genome of humans and can change the genetic structure during cell division. After their integration into the DNA, significant changes in the normal functioning of DNA are observed, which lead to a myriad of disorders [30].

The genotoxicity of various compounds has been found in various plant families, such as retrorsine and heliotrine in Boraginaceae, Compositae (Asteraceae), and Leguminosae (Fabaceae) [7,34], Safrole has been detected in Lauraceae and Myristicaceae [35-37]. Myristicin has been reported in Myristicaceae, and estragole found in Asteraceae [38]. Therefore, MPs need to be tested to ensure their safety for human use and to prevent side effects.

\subsection{Clastogenicity and Carcinogenicity of Medicinal Plants}

A clastogen is an agent that can induce structural variations. In chromosomes, a clastogen causes breaks that result in the loss, gain, or rearrangements in the segments of chromosomes. A clastogen can also cause exchanges in sister chromatids during the replication of DNA [39]. The difference between this and mutagenicity is that clastogenicity occurs at the chromosome level. A clastogen is regarded as a substance that results in the loss or rearrangement of the chromosome segments by causing breaks. During the processes of mitosis, meiosis, or DNA replication, clastogens can also cause exchanges or 
interchanges and reunions of the sister chromatids. X-ray and UV radiation, and certain anti-cancerous drugs like benzene, ethylene oxide, and inorganic clastogens are some of the examples of known human clastogens [40].

The definition of carcinogenicity, according to the American Cancer Society, is any substance that raises the risk of cancer or a tumor in an organism, such as direct exposure to radiation, high toxic metal content, and bad habits such as excessive consumption of alcoholic beverages and tobacco and its derivatives. However, the carcinogen does not always cause cancer. Doses differ from one person to another, and cancer does not occur unless there is a change in the genetic makeup, and it is possible that a very small dose of some agents causes cancer in some people while others must be exposed for years before cancer occurs [41].

Carcinogens are divided into groups according to their risk to humans. These groups are categorized by the International Agency for Research on Cancer (IARC). The first group is classified as carcinogenic to humans and contains 120 agents. The second group is divided into sections $2 \mathrm{~A}$ and $2 \mathrm{~B}$. Section $2 \mathrm{~A}$ is probably carcinogenic to humans and contains 83 agents. Section $2 \mathrm{~B}$ is possibly carcinogenic to humans and contains 314 agents. The third group contains 500 agents that are not classifiable as to their carcinogenicity to humans (Table 1). Cancer is divided according to the cancer site with enough or limited evidence in humans. For example, there is enough evidence that smoking and X-ray radiation are causes of kidney cancer. On the other hand, there are agents with limited evidence, such as $\mathrm{Cd}$ and its compounds [30,41].

Table 1. The data show cases of different chemicals that have the potential to cause cancer.

\begin{tabular}{cc}
\hline Chemical & Carcinogenicity \\
\hline EMS & + \\
\hline HN2 & + \\
\hline DES & + \\
\hline HMPA & + \\
\hline Benzene & $+/-$ \\
\hline EO & - \\
\hline DMF & + \\
\hline DMN & - \\
\hline 4 CMB & - \\
\hline IsoPC &
\end{tabular}

A carcinogen, as mentioned earlier, is any substance or agent that causes cancer or raises the risk of cancer. A carcinogen can be categorized into two sections: genotoxic and non-genotoxic. The agents or chemical substances that induce tumors by interacting with DNA strands or chromosomes are both genotoxic and carcinogenic, and may induce mutations in the structure of chromosomes and genes, thus causing genomic mutations. This is called genotoxicity [42]. The mutator phenotype means an increase in the rate of mutation in cancerous cells. The mutator phenotype hypothesis was constructed to consider the discrepancy between the large number of mutations observed in human tumor cells and the frequency of spontaneous mutations in normal cells. This hypothesis states that the mutation rate accelerates in the early stages of tumor formation [43].

The carcinogenicity of many compounds has been reported in plants. For instance, aristolochic acids I and II have been detected in Aristolochiaceae [44,45], and pyrrolizidine alkaloids have been found in Boraginaceae, Compositae (Asteraceae), and Leguminosae (Fabaceae) [7,34]. Moreover, alkenylbenzenes have been observed in Lauraceae and Myristicaceae [37]. Thus, carcinogenic compounds in medicinal herbs must be characterized and determined to be safe for human use. 


\section{Nanoparticles from Plant Extracts}

Nanoparticles (NPs) are compounds extracted from many types of MPs and are found in different proportions. The nanomaterials are divided into two parts. The first part, nano, means an NP whose size ranges from 1 to $100 \mathrm{~nm}$. The nanometer is the unit of measurement for these nanomaterials. The second part, material, according to the dictionary, means the substance of which a thing is made or composed [46]. Nanoparticles can be divided according to size; for example, atoms and small molecules are $0.1 \mathrm{~nm}$, NPs are 1 to $100 \mathrm{~nm}$, and fine particles (also called particulate matter: PM-2.5) are 100 to $2500 \mathrm{~nm}$, and so on until we reach paper thickness [47].

There are many shapes of nanomaterials in plants, such as rods, tubes, spheres, micelles and shells. There are also many groups divided into categories. For example, the carbon-based category contains many nanoscale materials, such as fullerenes and carbon nanotubes; the metal category contains $\mathrm{Ag}, \mathrm{Au}$, and $\mathrm{Al}$; and the metal oxide category contains $\mathrm{CuO}, \mathrm{ZnO}, \mathrm{Fe}_{2} \mathrm{O}_{3}, \mathrm{TiO}_{2}, \mathrm{SiO}_{2}$, etc. There are also many other categories, all of which are extracted from different plant species or algae, and of course there are benefits and harms [48].

\section{Nanomaterial Interaction with Tissues}

In plants, the interaction with nanomaterials takes place in several ways. Nanomaterial interaction in animal cells is more well studied, with interaction in plants being less well known. However, it can be divided into five suggested ways (Figure 1): 1. Endocytosis: NPs are adsorbed by invagination of the plasma membrane (PM) into the cells. A vesicle that can move between the compartments of cells. 2. Pore formation: some NPs may interfere with the PM, induce the pore formation to pass through the cell and directly reach the cytosol without being encapsulated in any organelle. 3. Carrier proteins: NPs bind to proteins, including cell membrane proteins that act as carriers for intercellular traffic. The aquaporins are regarded as NP-specific transporters within the cell. However, their small pore size ( 2.8 and $3.4 \AA$ ) makes them unfit to be used as channels for NP penetration. 4. Plasmodesmata: another means for nanomaterials to enter a cell, and is a complex mechanism for transport. 5. Ion channels: a possible route for the entrance of NPs into the cell. However, the size of such channels is around $1 \mathrm{~nm}$, which makes it very unlikely that NPs will be able to cross through them effectively without undergoing major modifications [49].

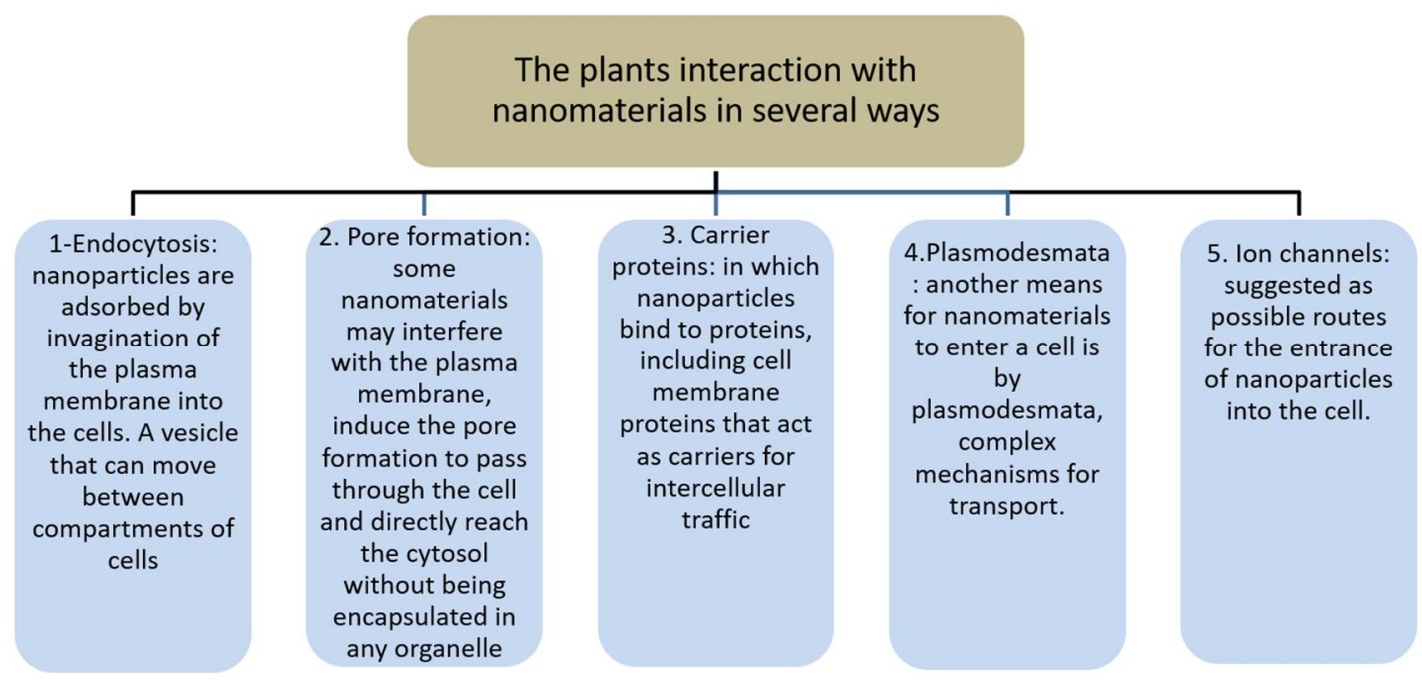

Figure 1. Plants interact with nanomaterials in several ways.

Another example is the interaction of NPs with blood components like red blood corpuscles. We find that recent results have described the tendency of erythrocytes to act 
as carriers of NPs. They tend to bind to the vascular endothelium and act as a conduit to circumvent the immune system. The erythrocytes have physical and chemical properties that are suitable for drug delivery. Based on the cell-based therapy data, erythrocytes are considered the most versatile, safe, stable, and easy to manufacture cells. This property of erythrocytes is based on the temporary opening of pores in the erythrocyte membrane, the ease of drug transportation, and the capability of erythrocytes to stay within these types of cells once the pores are closed. Thus, there is no doubt as to the hemolytic nanomaterials' potential, and because long-term hemolysis can have devastating health consequences, an evaluation of the potential of hemolytic nanomaterials is very important. Another component of the blood is platelets: cells meet a substance, bind to its surface, and initiate a cascade of signaling events that can slowly cause the cross-linking of fibrins and formation of clots. While platelet binding is one of the key mechanisms that prevent hemostasis and avoid hemorrhage, it may also lead to the emergence of potentially dangerous thrombi that can cause stroke. Thrombus formation involves the participation of molecular components in a series of cellular events in particular proteins. When a nanomaterial causes platelet aggregation and changes the normal cycle of coagulation, it can lead to bleeding or thrombosis. It is therefore necessary to know the thrombogenic potential of each form of nanomaterial, particularly in the case of considering their future uses in nano-biomedicine.

Unfortunately, there are few studies on the relationship between nanoparticles and platelets; this makes them ideal for therapists. Like several types of nanoparticles that can induce the activation of platelets, some of the nanomaterials are utilized for diagnosing thrombotic disease, as the size of the thrombogenic proteins range from nanometers to micrometers. High-resolution analysis is required to diagnose these types of proteins in real-time, and this can be achieved by the usage of nano-transporters. For example, liposomes contain thrombin inhibitors for acute thrombosis, perfluorocarbon nanoparticles with thrombin modifiers, polymer nanoparticles with antithrombotic involvement, magnetic nanoparticles conjugated with thrombolytic response urokinase, and $\mathrm{Fe}_{2} \mathrm{O}_{3}$ nanoparticles conjugated with plasminogen activator for thrombosis. The identification of the prothrombotic or nano-transporting ability of nanomaterials is important for their applicability in medical implications [50]. In another example of using nanoparticles, carbon-based nanomaterials were used to build new bone on small black scaffolds, and the researchers concluded that carbon can be applied biologically and is mechanically stable for use in tissue engineering. There are many nanocarbons that we can use to repair bone; however, studies on these and other nanomaterials should be increased as the risks are unknown, and there remains the possibility that they will cause cytotoxicity [51].

\section{Mechanisms of Nanoparticle-Induced Genotoxicity}

Nanoparticles are extracted from medicinal plants and are called green nanoparticles. In this section, we will discuss their types, harms, and their relationship with genotoxicity. As already mentioned, nanoparticles range in size from 1 to $100 \mathrm{~nm}$ and have different shapes. Nanoparticles also have unique chemical and physical properties. Green nanoparticles can be taken from any part of the plant, such as the stem, leaves, roots, seeds, and fruits. They can also be taken from algae, fungi, and different types of bacteria [52]. Gold nanoparticles (Au-NPs) can be extracted from specific plants, such as Jatropha curcas, Quercus virginiana, Magnolia grandiflora, and Pueraria lobate; these NPs can be extracted from all parts of the plant. Silver nanoparticles can be extracted from Acalypha indica, Rhizophora mucronate, and Mentha piperita, again from all parts of the plant [53], along with noble metal nanoparticles and metal oxide nanoparticles, such as $\mathrm{TiO}_{2}, \mathrm{ZnO}$, and $\mathrm{MgO}$ [54]. In this section we will also talk about the mechanism and method of genotoxicity occurrence in genetic material.

There are many mechanisms of nanoparticles that cause genotoxicity (Figure 2): 1. direct genotoxicity: this results from physical interactions with DNA. For example, the effect of stacking forces among DNA bases, the phosphorylation impact, the creation of adducts, or the alteration of gene expression or regulation, hydrophobicity, and NP surface 
loading are essential considerations in assessing genotoxicity. Upon passing through the membrane of cells and eventually disseminating or transmitting across the membrane of the nucleus via the nuclear pore complexes, NPs form bonds directly with the DNA during interphase. The NPs that cross the cellular and nuclear membranes by the processes of diffusion or endocytosis interact with the DNA directly using the replication effect, through transcription or conformation in DNA structures either mechanically or by chemical bonding to DNA, or during mitosis. NPs connect with the chromosomes that cause clastogenic (chromosomal breakage) or aneugenic (chromosome loss) effects either mechanically or by chemically binding to DNA.

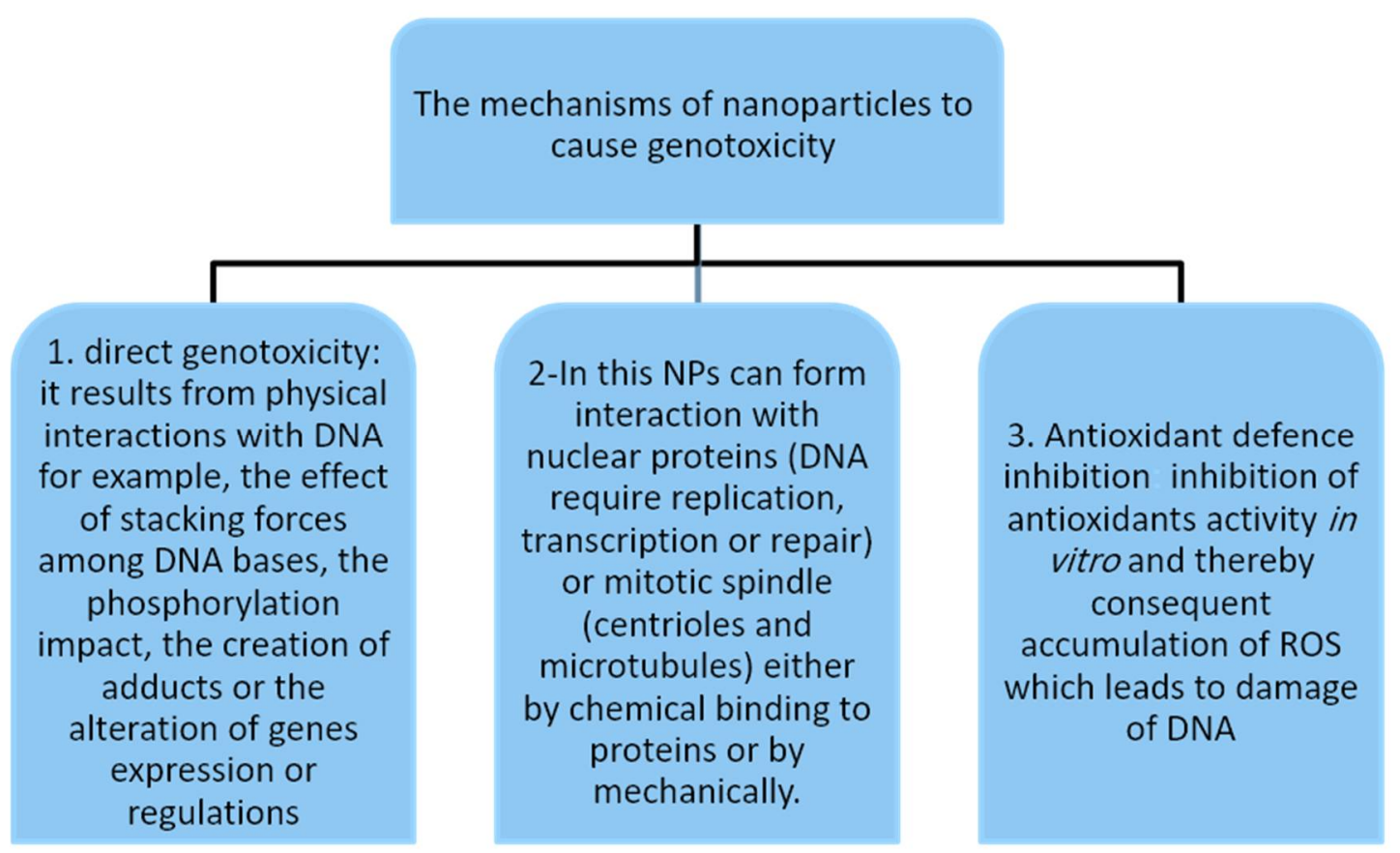

Figure 2. The mechanisms of nanoparticles that cause genotoxicity.

In this way, NPs can interact with nuclear proteins (DNA requires replication, transcription, or repair) or the mitotic spindle (centrioles and microtubules) either mechanically or by chemically binding to proteins. NPs can also interrupt the checkpoints of the cell cycle, interfere with an antioxidant enzyme, or cause ROS production by either mechanical or cellular components. 3. Antioxidant defense inhibition: inhibition of antioxidant activity in vitro and thereby consequent accumulation of ROS, which leads to DNA damage, for instance, the glutathione interaction with NPs as the major non-enzymatic antioxidants. According to [55], the derived NPs of silicon carbide are known to deplete the glutathione level and cause the inactivation of glutathione reductase and superoxide dismutase. There are many uses for silver nanoparticles, such as antibacterial purposes, use in drug-delivery systems and for catheter modification, dental applications, wound healing, and bone healing, among other medical uses [56]. Each method has a mechanism to detect genotoxicity; there are several assays, such as the chromosome aberration test, cytokinesis-blocked micronucleus assay, Ames test, comet assay, HPRT forward mutation assay, and other tests.

According to a study conducted to detect the genotoxicity of silver nanoparticles, when doing tests in in vitro and in vivo on breast cancer cells, an increase in DNA damage and a decrease in the number of cells was observed. In another study, the time and dosage-dependent AgNPs' genotoxic effects on human lung cells were examined, with the oral exposure of Ag-NPs to mice suggesting that induction of deletions of DNA in the development of embryos took place, along with chromosomal damage in bone marrow that was correctable, DSB and oxidative DNA damage, and DNA repair gene expression 
system modulation. It was found that the downregulation of baseline excision repair (BER) enhances cancer susceptibility [57].

\section{Carcinogenicity, Nanoparticles and Plants: A Significant Integration}

Contrary to the established methodologies of cancer treatment, there is an emergent concern toward developing cheaper and more cost-effective therapeutic agents using natural resources such as plants $[58,59]$. Medicinal plants have delivered new horizons for the treatment of cancer. They are not only a valuable resource for new chemical compounds through bioprospecting, but they also provide novel strategies for the treatment of cancer, like green synthesis of silver nanoparticles (AgNPs). In this respect, nanotechnology carries the potential to be applied at the molecular level to address specific issues. It is a dynamic field, involving the biology, chemistry, and physics of the nanoscale objects. Remarkable research in nanotechnology has opened up new avenues for drug delivery, treatment, and diagnosis [60]. Nanotechnology, coupled with metal nanoparticles, has been successfully applied in various fields, especially in biomedical sciences. In terms of treatment and diagnosis, nanoparticles are utilized due to their shape, size, and unique optical and thermal characteristics [61].

These exceptional properties of metal nanoparticles, which are due to their size and elevated surface area-to-volume ratio, make them ideal for many biological applications, including theranostics [62]. These distinctive features are not exhibited by their macro-scale counterparts. The synthesis of nanoparticles can be carried out using different techniques via physical and chemical methods. However, recent research indicates that biological methods have played a significant role in the synthesis of metal nanoparticles [63], Living organisms such as fungi and bacteria can be used to synthesize nanoparticles, but the synthesis platform involving plants provides an ecofriendly and adequate approach because it is devoid of the use of many expensive, toxic, and harmful chemical compounds in the growth media [64]. Other advantages of plant-derived nanoparticles include rapid synthesis, increased stability, and cost-effectiveness. In addition, nanoparticles of several sizes and shapes can be produced more easily using plants compared to other organisms [65]. Unlike bacteria and fungi that require relatively long incubation times for the reduction of metal ions, phytochemicals can do it rather quickly and eliminate the need for expensive and time-consuming downstream processing. Green synthesis resources like fungi and bacteria trigger biosafety issues that are neutralized by using plants for green synthesis [66]. Therefore, plant-based platforms for green synthesis are the best candidates for synthesizing metal nanoparticles [67].

\section{Conclusions}

Genotoxicity data have been created for number of medicinal plants, but few herbs show carcinogenic effects. Carcinogenicity evidence is also scarce, and health information is still focused on testing for genotoxicity. However, certain carcinogens have still not been detected, which yields an unsatisfying result [1]. Medicinal herbs are contributing to primary health care in diverse parts of the world. In areas where the supply of therapeutic alternatives is limited, herbal medicines can act an essential part of primary health care. In highly developed countries, herb-derived remedies are being used frequently.

There is a growing interest in the introduction of alternative therapies, which also includes herbal medicines as a therapeutic alternative alongside, for example, diet, physical therapy, or therapeutic activity. However, when medicinal plants are used, there is a basic requirement for quality, efficacy, and safety to be taken into consideration. Recently, the genotoxicity and carcinogenicity of herbal medicines have received attention, and guidelines require genotoxicity tests and validation by administrations and committees to ensure public health from toxic plants. For example, the European Medicines Agency (EMA) has implemented the "Guideline on non-clinical documentation for herbal medicinal products in applications for marketing authorization and in applications for registration", an established procedure for assessing the genotoxicity of herbal medicinal products [68]. 
The Saudi Food and Drug Authority (SFDA) launched the "Saudi FDA Products Classification Guidance including Herbal Products" regulations [69]. Moreover, the SFDA implemented market authorization for herbal products if they are used for medical purposes. For instance, products containing pyrethrum, pyrethrins, or alkaloids need to be authorized before being distributed in the market. Unfortunately, few studies are concerned with the carcinogenicity of nanoparticles of medicinal plants, whereas many researchers are interested in genotoxicity assessment; thus, there is a need for more studies of medicinal plants and their nanoparticles. Moreover, the general public must be educated about the genotoxicity and carcinogenicity of medicinal plants to raise awareness and minimize the risk of misuse.

Author Contributions: For Conceptualization, methodology, validation S.H.Q., formal analysis S.H.Q. and M.H.S., resources, data curation A.F.A., writing_-original draft preparation S.H.Q., A.F.A. and A.B.A., writing-review and editing S.H.Q. and M.H.S. All authors have read and agreed to the published version of the manuscript.

Funding: This research was funded by Deanship of Scientific Research at Umm Al-Qura University, grant number (19-SCI-1-01-0009). The APC was funded by S.H.Q. and A.F.A.

Institutional Review Board Statement: Not applicable.

Informed Consent Statement: Not applicable.

Data Availability Statement: This data is relevant to this research.

Conflicts of Interest: The authors consider themselves clear of any conflict of interest.

\section{References}

1. Poivre, M.; ENachtergael, A.; Bunel, V.; Philippe, O.; Duez, A. Genotoxicity and carcinogenicity of herbal products. In Toxicology of Herbal Products; Pelkonen, O., Duez, P., Vuorela, P.M., Vuorela, H., Eds.; Springer: Cham, Switzerland, 2017; pp. 179-215.

2. Zhou, J.; Ouedraogo, M.; Qu, F.; Duez, P. Potential genotoxicity of traditional Chinese medicinal plants and phytochemicals: An overview. Phytother. Res. 2013, 27, 1745-1755. [CrossRef] [PubMed]

3. Sponchiado, G.; Adam, M.L.; Silva, C.D.; Soley, B.S.; de Mello-Sampayo, C.; Cabrini, D.A.; Correr, C.J.; Otuki, M.F. Quantitative genotoxicity assays for analysis of medicinal plants: A systematic review. J. Ethnopharmacol. 2016, 178, 289-296. [CrossRef] [PubMed]

4. Buzea, C.; Pacheco, I.I.; Robbie, K. Nanomaterials and nanoparticles: Sources and toxicity. Biointerphases 2007, 2, MR17-MR71. [CrossRef] [PubMed]

5. Saravanan, M.; Asmalash, T.; Gebrekidan, A.; Gebreegziabiher, D.; Araya, T.; Hilekiros, H.; Barabadi, H.; Ramanathan, K. Nano-medicine as a newly emerging approach to combat human immunodeficiency virus (HIV). Pharm. Nanotechnol. 2018, 6, 17-27. [CrossRef]

6. Barabadi, H.; Mahjoub, M.A.; Tajani, B.; Ahmadi, A.; Junejo, Y.; Saravanan, M. Emerging theranostic biogenic silver nanomaterials for breast cancer: A systematic review. J. Clust. Sci. 2019, 30, 259-279. [CrossRef]

7. Wang, Y.P.; Yan, J.; Beger, R.D.; Fu, P.P.; Chou, M.W. Metabolic activation of the tumorigenic pyrrolizidine alkaloid, monocrotaline, leading to DNA adduct formation in vivo. Cancer Lett. 2005, 226, 27-35. [CrossRef]

8. Barabadi, H.; Kobarfard, F.; Vahidi, H. Biosynthesis and characterization of biogenic tellurium nanoparticles by using Penicillium chrysogenum PTCC 5031: A novel approach in gold biotechnology. Iran. J. Pharm. Res. 2018, 17, 87-97.

9. Barabadi, H. Nanobiotechnology: A promising scope of gold biotechnology. Cell. Mol. Biol. 2017, 63, 3-4. [CrossRef]

10. Barabadi, H.; Honary, S.; Ebrahimi, P.; Alizadeh, A.; Naghibi, F.; Saravanan, M. Optimization of myco-synthesized silver nanoparticles by response surface methodology employing Box-Behnken design. Inorg. Nano-Met. Chem. 2019, 49, 33-43. [CrossRef]

11. Salari, S.; Esmaeilzadeh Bahabadi, S.; Samzadeh-Kermani, A.; Yousefzaei, F. In vitro evaluation of antioxidant and antibacterial potential of green synthesized silver nanoparticles using Prosopis farcta fruit extract. Iran. J. Pharm. Res. 2019, 18, 430-445.

12. Dobrucka, R. Synthesis of titanium dioxide nanoparticles using Echinacea purpurea herba. Iran. J. Pharm. Res. 2017, 16, 753-759.

13. El-Rafie, H.M.; Zahran, M.K. Green synthesis of silver nanoparticles using polysaccharides extracted from marine macro algae. Carbo Polym. 2013, 96, 403-410. [CrossRef]

14. Tichy, J.; Novak, J. Extraction, assay, and analysis of antimicrobials from plants with activity against dental pathogens (Streptococcus sp.). J. Altern. Complement. Med. 1998, 4, 39-45. [CrossRef]

15. Honary, S.; Barabadi, H.; Ebrahimi, P.; Naghibi, F.; Alizadeh, A. Development and optimization of biometal nanoparticles by using mathematical methodology: A microbial approach. J. Nano Res. 2015, 30, 106-115. [CrossRef] 
16. Rezvani Amin, Z.; Khashyarmanesh, Z.; Fazly Bazzaz, B.S.; SabetiNoghabi, Z. Does biosynthetic silver nanoparticles are more stable with lower toxicity than their synthetic counterparts? Iran. J. Pharm. Res. 2019, 18, 210-221. [PubMed]

17. Barabadi, H.; Alizadeh, A.; Ovais, M.; Ahmadi, A.; Shinwari, Z.K.; Saravanan, M. Efficacy of green nanoparticles against cancerous and normal cell lines: A systematic review and meta-analysis. IET Nanobiotechnol. 2018, 12, 377-391. [CrossRef] [PubMed]

18. Didry, N.; Dubreuil, L.; Trotin, F.; Pinkas, M. Antimicrobial activity of aerial parts of Drosera peltata Smith on oral bacteria. J. Ethnopharmacol. 1998, 60, 91-96. [CrossRef]

19. Benarba, B.; Pandiella, A. Medicinal plants as sources of active molecules against COVID-19. Front. Pharmacol. 2020, 11, 1189. [CrossRef]

20. Cosyns, J.P.; Jadoul, M.; Squifflet, J.P.; Wese, F.X.; de Strihou, C.V.Y. Urothelial lesions in Chinese-herb nephropathy. Am. J. Kidney Dis. 1999, 33, 1011-1017. [CrossRef]

21. Ernst, E. Toxic heavy metals and undeclared drugs in Asian herbal medicines. Trends Pharmacol. Sci. 2002, 23, 136-139. [CrossRef]

22. Ekor, M. The growing use of herbal medicines: Issues relating to adverse reactions and challenges in monitoring safety. Front. Pharmacol. 2014, 4, 177. [CrossRef]

23. Fard, J.K.; Hamzeiy, H.; Sattari, M.; Eftekhari, A.; Ahmadian, E.; Eghbal, M.A. Triazole rizatriptan induces liver toxicity through lysosomal/mitochondrial dysfunction. Drug Res. 2016, 66, 470-478. [CrossRef] [PubMed]

24. Ahmadian, E.; Babaei, H.; Nayebi, A.M.; Eftekhari, A.; Eghbal, M.A. Mechanistic approach for toxic effects of bupropion in primary rat hepatocytes. Drug Res. 2017, 67, 217-222. [CrossRef]

25. Phillips, D.H.; Arlt, V.M. Genotoxicity: Damage to DNA and its consequences. In Molecular, Clinical and Environmental Toxicology; Springer: Cham, Switzerland, 2009; pp. 87-110.

26. Mohamed, S.; Sabita, U.; Rajendra, S.; Raman, D. Genotoxicity: Mechanisms, testing guidelines and methods. Glob. J. Pharm. Sci. 2017, 1, 555-575.

27. Caballero, B.; Trugo, L.C.; Finglas, P.M. Encyclopedia of Food Sciences and Nutrition; Academic Press: San Diego, CA, USA, 2003.

28. Dhawan, A.; Shanker, R.; Kumar, A.; Dobrovolsky, V.N. Mutagenicity: Assays and Applications; Academic Press: London, UK, 2018.

29. Kodym, A.; Afza, R. Physical and chemical mutagenesis. Plant Funct. Genom. 2015, 189-204. [CrossRef]

30. IARC. Agents Classified by the IARC. Available online: https://monographs.iarc.fr/agents-classified-by-the-iarc/ (accessed on 16 November 2021).

31. Biology Discussion. Types of Mutagens. 2016. Available online: Https://www.biologydiscussion.com/genetics/types-ofmutagens-chemical-and-physical-genetics / 65297 (accessed on 16 November 2021).

32. CDC. Facts about Sodium Azide. 2018. Available online: https://emergency.cdc.gov/agent/sodiumazide/basics/facts.asp (accessed on 22 May 2020).

33. Olsen, O.; Wang, X.; Wettstein, D.V. Sodium azide mutagenesis: Preferential generation of A.T->G.C transitions in the barley Ant18 gene. Proc. Natl. Acad. Sci. USA 1993, 90, 8043-8047. [CrossRef]

34. Fu, P.; Xia, Q.; Lin, G.; Chou, M. Genotoxic pyrrolizidine alkaloids-mechanisms leading to DNA adduct formation and tumorigenicity. Int. J. Mol. Sci. 2002, 3, 948-964. [CrossRef]

35. Segelman, A.B.; Segelman, F.P.; Karliner, J.; Sofia, R.D. Sassafras and herb tea: Potential health hazards. JAMA 1976, $236,477$. [CrossRef] [PubMed]

36. Thomas, S.J.; MacLennan, R. Slaked lime and betel nut cancer in Papua New Guinea. Lancet 1992, 340, 577-578. [CrossRef]

37. Chen, C.L.; Chi, C.W.; Chang, K.W.; Liu, T.Y. Safrole-like DNA adducts in oral tissue from oral cancer patients with a betel quid chewing history. Carcinogenesis 1999, 20, 2331-2334. [CrossRef]

38. Barnes, J.; Anderson, L.; Phillipson, D.; Smith, M.; Veitch, N.C. Herbal Medicines; Pharmaceutical Press: London, UK, 2007.

39. Hewitt, J.B. Effects of Occupational Exposure to Antineoplastic Drugs; University of Wisconsin: Madison, WI, USA, 1997.

40. ILPI. Clastogen. 2020. Available online: http:/ / www.ilpi.com/msds/ref/clastogen.html (accessed on 16 November 2021).

41. Baan, R.; Straif, K.; Grosse, Y.; Secretan, B.; el Ghissassi, F.; Bouvard, V.; Altieri, A.; Cogliano, V. Carcinogenicity of alcoholic beverages. Lancet Oncol. 2007, 8, 292-293. [CrossRef]

42. European Commission. Scientific Opinion on the Risk Assessment Methodologies and Approaches for Genotoxic and Carcinogenic Substances. 2009. Available online: https:/ / ec.europa.eu/health/ph_risk/committees/04_scher/docs/scher_o_113.pdf (accessed on 16 November 2021).

43. Loeb, L. Mutator Phenotype. 1970. Available online: https://link.springer.com/referenceworkentry/10.1007/978-3-642-16483-5_ 3913 (accessed on 7 June 2020).

44. Debelle, F.D.; Vanherweghem, J.L.; Nortier, J.L. Aristolochic acid nephropathy: A worldwide problem. Kidney Int. 2008, 74, 158-169. [CrossRef]

45. Nortier, J.; Pozdzik, A.; Roumeguere, T.; Vanherweghem, J.-L. Néphropathie aux Acidesaristolochiques (“Néphropathie aux Herbes Chinoises"). EMC—Néphrologie 2013, 10, 1-14. [CrossRef]

46. Dictionary. 2020. Available online: Https://www.dictionary.com/browse/materials (accessed on 16 November 2021).

47. Robertson, J.; Rizzello, L.; Avila-Olias, M.; Gaitzsch, J.; Contini, C.; Magon, M.; Renshaw, S.; Battaglia, G. Purification of nanoparticles by size and shape. Sci. Rep. 2016, 6, 27494. [CrossRef]

48. Sanzari, I.; Leone, A.; Ambrosone, A. Nanotechnology in plant science: To make a long story short. Front. Bioeng. Biotechnol. 2019, 7, 120. [CrossRef] 
49. Pérez-De-Luque, A. Interaction of nanomaterials with plants: What do we need for real applications in agriculture? Front. Environ. Sci. 2017, 5, 12. [CrossRef]

50. Cruz, G.G.; Rodríguez-Fragoso, P.; Reyes-Esparza, J.; Rodríguez-López, A.; Gómez-Cansino, R.; Rodriguez-Fragoso, L. Interaction of nanoparticles with blood components and associated pathophysiological effects. In Unraveling the Safety Profile of Nanoscale Particles and Materials_From Biomedical to Environmental Applications; IntechOpen: London, UK, 2018.

51. Eivazzadeh-Keihan, R.; Maleki, A.; Guardia, M.D.; Bani, M.S.; Chenab, K.K.; Pashazadeh-Panahi, P.; Hamblin, M.R. Carbon based nanomaterials for tissue engineering of bone: Building new bone on small black scaffolds: A review. J. Adv. Res. 2019, 18, 185-201. [CrossRef] [PubMed]

52. Durán, N.; Alves, O.L.; Zucolotto, V.; Guterres, S. Nanotoxicology: Materials, Methodologies, and Assessments; Springer: New York, NY, USA, 2014.

53. Mumtaz, A.; Mohammad, A.; Shahverdi, A.R. Role of natural products in green synthesis of nanoparticles. In Green Biosynthesis of Nanoparticles: Mechanisms and Applications; CABI: São Paulo, Brazil, 2013; pp. 31-52.

54. Küünal, S.; Rauwel, P.; Rauwel, E. Plant extract mediated synthesis of nanoparticles. In Emerging Applications of Nanoparticles and Architecture Nanostructures; Elsevier: Amsterdam, The Netherlands, 2018; pp. 411-446.

55. Mehrian, S.K.; Lima, R.D. Nanoparticles cyto and genotoxicity in plants: Mechanisms and abnormalities. Environ. Nanotechnol. Monit. Manag. 2016, 6, 184-193.

56. Burdușel, A.; Gherasim, O.; Grumezescu, A.M.; Mogoantă, L.; Ficai, A.; Andronescu, E. Biomedical applications of silver nanoparticles: An up-to-date overview. Nanomaterials 2018, 8, 681. [CrossRef]

57. Patlolla, A.K.; Tchounwou, P.B. Genotoxicity of silver nanoparticles (Ag-NPs) in in vitro and in vivo models. In Nanotechnology in Skin, Soft Tissue, and Bone Infections; Springer: Cham, Switzerland, 2020; pp. 269-281.

58. Patra, C.R.; Mukherjee, S.; Kotcherlakota, R. Biosynthesized silver nanoparticles: A step forward for cancer theranostics? Nanomedicine 2014, 9, 1445-1448. [CrossRef] [PubMed]

59. Khan, T.; Khan, M.A.; Nadhman, A. Synthesis in plants and plant extracts of silver nanoparticles with potent antimicrobial properties: Current status and future prospects. Appl. Microbiol. Biotechnol. 2015, 99, 9923-9934.

60. Klefenz, H. Nanobiotechnology: From molecules to systems. Eng. Life Sci. 2004, 4, 211-218. [CrossRef]

61. Salata, O.V. Applications of nanoparticles in biology and medicine. J. Nanobiotechnol. 2004, 2, 1. [CrossRef]

62. Bhatte, K.D.; Deshmukh, K.M.; Patil, Y.P.; Sawant, D.N.; Fujita, S.-I.; Arai, M.; Bhanage, B.M. Synthesis of powdered silver nanoparticles using hydrogen in aqueous medium. Particuology 2012, 10, 140-143. [CrossRef]

63. Rai, M.; Ingle, A.; Gaikwad, S. Fungi: Myconanofactory, mycoremediation and medicine. In Fungi: Applications and Management Strategies; CRC Press: Boca Raton, FL, USA, 2016.

64. Shankar, S.S.; Rai, A.; Ankamwar, B.; Singh, A.; Ahmad, A.; Sastry, M. Biological synthesis of triangular gold nanoprisms. Nat. Mater. 2004, 3, 482-488. [CrossRef] [PubMed]

65. Iravani, S. Green synthesis of metal nanoparticles using plants. Green Chem. 2011, 13, 2638-2650. [CrossRef]

66. Kumar, V.; Yadav, S.K. Plant-mediated synthesis of silver and gold nanoparticles and their applications. J. Chem. Technol. Biotechnol. 2009, 84, 151-157. [CrossRef]

67. Rath, M.; Panda, S.S.; Dhal, N.K. Synthesis of silver nano particles from plant extract and its application in cancer treatment: A review. Int. J. Plant Anim. Environ. Sci. 2016, 4, 137-145.

68. EMEA. Guideline on the Assessment of Genotoxicity of Herbal Substances/Preparations. 2008. Available online: http://www.ema. europa.eu/docs/en_GB/document_library/Scientific_guideline/2009/09/WC500003569.pdf (accessed on 16 November 2021).

69. SFDA. Saudi FDA Products Classification Guidance. 2020. Available online: https://old.sfda.gov.sa/ar/oper/Documents/ SFDAProductsClassificationGuidance.pdf (accessed on 16 November 2021). 